\title{
FIGURAS DA MATERNIDADE EM CLARICE LISPECTOR OU A MATERNIDADE PARA ALÉM DO FALO
}

Cristina Marcos

Psicanalista; mestre em Literatura Brasileira, DEA em Psicanálise - Estudos Clínicos pela Universidade de Paris 8; e Doutora em Psicanálise e Psicopatologia Fundamental na Universidade de Paris 7; professora da PUC-Minas.
RESUMO: A maternidade é freqüentemente situada na lógica fálica. Nossa proposta é nos interrogarmos sobre o que, da maternidade e da gestação, não se reduz ao falo. As figuras da maternidade em Clarice Lispector exibem o que há aí de incomensurável, de impossível a simbolizar e aparecem ligadas ao mundo orgânico, ou, ainda, a um gozo animal e excessivo, lembrando o que Lacan nomeia como gozo outro. A criança é, para a mulher, um modo de relação com o falo, e não dizemos o contrário, entretanto Clarice nos dá a ver que a criança torna também presente um real incomensurável.

Palavras-chave: Maternidade, lógica fálica, gozo feminino e real.

ABSTRACT: The figures of motherhood in Clarice Lispector or motherhood beyond the phallus. Motherhood is often situated in a phallic logic. But something in motherhood is not reduced to the phallus. The figures of motherhood in Clarice Lispector shows what is incommensurable in it, what cannot be symbolized and is still linked to the organic world, to an animal and excessive jouissance. The child is, for the woman, a kind of relation with the phallus, but also the incommensurable real.

Keywords: Motherhood, phalic logic, feminine jouissance and real.

I

Freqüentemente a mãe não faz objeção à ordem fálica; ao contrário, ela se situa ao lado do falo, a criança sendo em geral enviada à equivalência freudiana criança-falo. A presença da criança, por meio dessa equação simbólica, viria tamponar a falta feminina. Conhecemos os destinos propostos por Freud para o Édipo feminino — a maternidade seria aquele que abriria o caminho à feminilidade (FREUD, 1931;1932/1969). Decepcionada pela mãe, a menina volta-se para o pai na esperança de ter o falo. $\mathrm{O}$ feminino e a histeria encontram-se na 
mesma lógica do desejo - a menina dirige-se ao pai, como aquele que detém o falo desejado, pedindo-lhe que a libere da sedução materna. A histeria pode ser entendida como uma resposta aos impasses provocados pela posição feminina, assim como a maternidade ou a mascarada.

O recobrimento constante feito entre a histeria, a maternidade e o feminino revelam a dificuldade da mulher em se situar, em se definir, fora da referência ao falo. Na falta de um significante que a nomeie, a histérica recorre ao falo. A posição histérica é tão somente uma resposta à falta de significante, para ser uma mulher, ela se dirige ao falo pela via da identificação. Nesse caso, ela se situa do lado do homem, cuja referência não é outra além do falo.

A significação da maternidade, para Freud, estaria na equivalência entre a criança e o falo como resposta à castração. Penso, aqui, na função de tamponamento do furo que a criança pode ter com relação à mãe. A criança, destinada a preencher a falta a ser da mãe, pareceria tecer um véu sobre a castração materna. $\mathrm{Na}$ interpretação de Lacan, a criança funcionaria como objeto tampão — objeto real que aparece na realidade funcionando como preenchimento do furo da castração (LACAN, 1969/1986). A criança, então, como tampa, se fazendo objeto, impossibilitaria o acesso da mãe à sua verdade. Entretanto, Clarice Lispector chama nossa atenção para outra face da maternidade que, ao invés de encobrir a castração, exibe o furo, o impossível recobrimento do real pelo simbólico, no que poderíamos chamar de a face de sombra da maternidade. As figuras da maternidade desenhadas em Clarice fazem pensar que a maternidade, via régia de um destino feminino marcado pelo falo, divide-se entre dois gozos, o gozo fálico e o gozo suplementar.

Embora Lacan permaneça freudiano no que se refere à premissa fálica afirmando a existência de uma só libido para os dois sexos e a impossibilidade de falarmos do inconsciente sem a referência ao falo, podemos ver um prenúncio do que ele chamará 'o não-todo feminino', já no texto de 1960 "Pour un congrès sur la sexualité féminine":

“Do mesmo modo, convém nos interrogarmos se a mediação fálica drena tudo o que pode se manifestar de pulsional na mulher, e notadamente toda a corrente do instinto materno. Por que não colocar aqui que o fato de que tudo que é analisável seja sexual não comporta que tudo o que é sexual seja acessível à análise?" (LACAN, 1960/1966, p. 730)

Nesta interrogação, chama nossa atenção a referência ao instinto materno como uma manifestação pulsional que não seria inteiramente mediada pelo falo. Temos, no seminário Encore (LACAN, 1972-1973/1975), a hipótese de que haveria algo de suplementar na mulher em relação ao falo. Lacan confirma por meio das 
fórmulas da sexuação que não há nem inconsciente feminino, nem tampouco libido feminina, há somente uma função para escrever as duas posições masculina e feminina, a função fálica. Entretanto, ele escreve, com o auxílio desta função, a possibilidade de um outro gozo que não se refere inteiramente ao falo. As fórmulas da sexuação são introduzidas por Lacan ao final do seu seminário D’un discours qui ne serait pas du semblant (1970-1971) e são desenvolvidas em Le savoir du psychanalyste (1971-1972), "L'étourdit" (1972/1973) e por fim no seminário Encore (1972-1972/1975), constituindo um esforço de formalização da diferença entre os sexos e inaugurando uma escrita capaz de postular a existência dos dois gozos.

Nossa hipótese é que o amor maternal é um amor possessão, marcado pelo gozo fálico, mas ele não se recobre inteiramente por esta ordem. Em que a maternidade confrontaria a mulher com a castração, ao invés de tamponá-la, como nos sugere Freud pela equivalênica criança-falo? Se seguimos o pensamento freudiano que propõe uma equivalência entre ser mulher e ser mãe, é a criança que vai servir para mediatizar a relação com o real. Para a mulher, uma resposta possível à castração é a criança, o que não é de modo algum semelhente ao modo como o homem responde à castração. Ele tem relação com uma representação do falo, o pênis, enquanto a mulher tem relação à produção de um objeto real - a criança.

A relação privilegiada das mulheres com o real pode ser entendida como a falta de representação do sexo feminino no inconsciente ou como o que é impossível de simbolizar. Entretanto, permanece a questão de se saber se o corpo feminino seria especialmente apropriado a esse lugar do S (de A barrado). O primeiro encontro com este fora do simbólico, com esse real estrangeiro, se faz para todo sujeito com a coisa materna. Este encontro faltoso, já que se trata de um corte radical entre o ser falante e o real, traz conseqüências para cada um.

O corpo da mãe permanece para sempre inacessível. Do seu corpo, podemos ter tão somente pedaços — a voz, o olhar, os toques, o perfume - ele permanece outro, estrangeiro. A criança pode tentar apropriar-se dele, comê-lo, cortá-lo, ele permance irredutivelmente outro. O impossível incesto com a coisa materna condena a criança a não ter nada além do que o objeto em pedaços — o seio, o olhar, a voz.

A palavra da mãe organiza o corpo pulsional, fornece significantes e coloca em jogo a dimensão do desejo e do falo. Contudo, o enigma de seu desejo desdobra o enigma do real do corpo. Ora, a mãe é, pelo seu corpo e pela sua palavra, o primeiro Outro, aquele por meio do qual a criança apreende a hiância do simbólico e o exílio inatingível do real. Não é surpreendente que o corpo feminino permaneça para sempre, para o homem e para a mulher, como o Outro absoluto. 
Há que se dizer que a mãe só pode ser situada como mulher a partir da descoberta da diferença sexual. No começo, o falo é atribuido à mãe tanto pelo menino quanto pela menina. É somente a partir da descoberta da castração da mãe que essa relação com o Outro será colocada na conta de uma relação com o feminino.

Mas temos aí uma outra questão. Essa relação à coisa materna é a mesma para o menino e para a menina? Que se passa para que eles se situem diferentemente em relação ao falo e ao real? E ainda: o que se passa para que as mulheres tenham uma relação privilegiada com o real da coisa materna?

Uma resposta possível seria dizer que a mulher engravida e que desse modo ela tem uma relação com a coisa materna pelo próprio corpo. Na gestação e no parto, trata-se sempre de um real incomensurável (SOLER, 2003). Podemos até mesmo dizer que uma mulher não encontra nunca sua mãe no parto, mas o insondável de um corpo outro, estrangeiro e gozador (LEMOINE-LUCCIONI, 1982 e KRISTEVA, 1999). A criança presentifica o desconhecido, o enigma, a face inacessível do Outro, mesmo se ela é também 'minha imagem e semelhança'. A prematuridade do pequeno ser humano, a ausência da linguagem, a inexistência de um aparelho instintual e a conseqüente montagem pulsional que se coloca em marcha, desenham a face inassimilável do Outro, fora do significado, estranho e estrangeiro a mim mesmo. O recém-nascido nos revela o hiato existente entre o eu e o Outro, na medida que nossa relação com o mundo e seus objetos não está dada pela determinação instintual, mas é marcada pela pulsão, resultado da necessidade humana ser atravessada pela linguagem.

Sabemos que uma mãe tem relação com seu filho como objeto erótico que se situa na cadeia de substituições simbólicas - seio, excremento, falo, criança. Sem dúvida, a criança é, para a mãe, um modo de relação com o falo. Contudo, parece-nos que o que está em jogo no casal mãe/criança não é inteiramente redutível à função fálica, na medida que a criança pode presentificar para a mãe a hiância do simbólico, a impossível conciliação entre o simbólico e o real, evidenciando que a língua em nós é adquirida. De fato, a criança, fazendo parte dos objetos da cadeia simbólica, é tomada na lógica fálica, mas ela também torna presente um real incomensurável. Podemos pensar nas depressões pós-parto como modos de manifestação deste real.

A maternidade é quase sempre situada em uma lógica fálica, sem no entanto reduzir-se a esta lógica (SILVESTRE, 1996). Resta, na gestação e na maternidade, alguma coisa de incomensurável, de real, de impossível de simbolizar. É este aspecto da maternidade, não inteiramente recoberto pelo falo, que se exibe nas figuras da maternidade em Clarice. O recém-nascido, mesmo se ele é desde sempre marcado pelo significante, presentifica uma vida orgânica, animal, pequeno pedaço de ser entre os gritos. 
Colette Soler sugere que exista a possibilidade de a criança representar para a mãe durante certo tempo "o encontro perpétuo com o que ela tem de mais particularmente feminino: o além do simbólico e os limites de todo saber" (SOLER, 2003, p. 281). A criança viria, assim, como pedaço de real, representar para a mãe o S (de A barrado). Desse modo, pelo seu corpo próprio, a mulher teria essa relação particular com o real. Lacan acrescenta que é dessa relação que elas gozam.

Pensar que a maternidade não se recobre de todo pela lógica fálica é pensar que ela está, de um lado, voltada para o falo, a criança tomada na equivalência simbólica falo-criança, e, de outro, voltada para S (de A barrado), a gestação, a maternidade e o parto revelando o encontro com um real incomensurável. É curioso então que o destino feminino por excelência, proposto por Freud como avatar do Penisneid, comporte, na verdade, algo que aponta para o que seria propriamente feminino em uma mulher, seu acesso a um gozo que não se reduz ao falo.

\section{II}

A figura da mulher que não pertence à sua vocação biológica é freqüente no universo de Clarice Lispector: Macabéia (LISPECTOR, 1984) tem os ovários murchos; G.H. (idem, 1996) os tem secos; Laura (idem, 1999) tem, no fundo de seus olhos, um pequeno ponto ofendido que revela a falta de filhos, os filhos que ela nunca teve; e assim é também Joana (idem, 1995), incapaz de fazê-los viver. As mulheres, em Clarice Lispector, parecem recuar diante do horror da maternidade, horror marcado pela carne viva, pelo orgânico, pelo que do real é refratário ao simbólico.

Elas não são essencialmente mães, como pode ser o caso, por exemplo, em Marguerite Duras, cuja obra é abundante em figuras maternas, sejam elas amáveis e dedicadas aos seus filhos até o esquecimento de si mesmas, como Anne Debarades em Moderato Cantabile (1993), sejam elas infanticidas e loucas, como a mendiga em India Song (1998).

Não que as mães estejam ausentes de seu universo, mas a maternidade aparece, na obra de Clarice, de modo particular: as mulheres são, em sua maioria, estéreis, abortadoras, incapazes de serem mães. A maternidade é freqüentemente ligada ao mundo orgânico, à matéria viva. Que se pense em A paixão segundo G.H., no qual a maternidade é situada não do lado de G.H., mas do lado da barata - G.H. tem os ovários vazios, enquanto a barata os tem férteis; ela é abortadora, a barata, mãe de milhares de filhos.

Os dois olhos da barata "eram vivos como dois ovários. Ela me olhava com a fertilidade cega de seu olhar. Ela fertilizava a minha fertilidade morta” (LISPECTOR, 1996, p.50). 
“Seus olhos continuavam monotonamente a me olhar, os dois ovários neutros e férteis. Neles eu reconhecia meus dois anôminos ovários neutros. E eu não queria, ah, como eu não queria!

(...) Eu seria obrigada a continuar a reconhecer. E reconhecia na barata o insosso da vez em que eu estivera grávida. (...)

- Lembrei-me de mim mesma andando pelas ruas ao saber que faria o aborto, doutor, eu que de filho só conhecia e só conheceria que ia fazer um aborto. Mas eu pelo menos estava conhecendo a gravidez. Pelas ruas sentia dentro de mim o filho que ainda não se mexia, enquanto parava olhando nas vitrines os manequins de cera sorridentes. E quando entrara no restaurante e comera, os poros de um filho devoravam como uma boca de peixe à espera. (...) Gravidez: eu fora lançada no alegre horror da vida neutra que vive e se move." (LISPECTOR, 1996, p. 59-60).

Ou ainda na prece na qual, ao final, mãe e barata convergem.

- Mãe: matei uma vida, e não há braços que me recebam agora e na hora do nosso deserto, amém. Mãe, tudo agora tornou-se duro. Interrompi uma coisa organizada, mãe, e isso é pior que matar, isso me fez entrar por uma brecha que me mostrou, pior que a morte, que me mostrou a vida grossa e neutra amarelecendo. A barata está viva, e o olho dela é fertilizante, estou com medo de minha rouquidão, mãe. (...)

- Mãe, eu só fiz querer matar, mas olha só o que eu quebrei: quebrei um invólucro! Matar também é proibido porque se quebra o invólucro duro, e fica-se com a vida pastosa. De dentro do invólucro está saindo um coração grosso e branco e vivo com puz, mãe, bendita sois entre as baratas, agora e na hora desta tua minha morte, barata e jóia." (LISPECTOR, 1996, p. 61)

No conto “A menor mulher do mundo" (LISPECTOR, 1999), temos uma figura bastante significativa da maternidade na obra de Clarice Lispector e do seu laço com o orgânico e com o primitivo. Nos confins da África, lugar ancestral, um antropólogo francês descobre a menor mulher do mundo, vivendo numa floresta do Congo Central, entre os seres de sua tribo quase desprovidos de linguagem - falam por frases simples, palavras pobres, gestos e gritos. Buscando apreender este outro desconhecido, como quem tateia na escuridão desejando ao menos que ela lhe seja familiar, o explorador nomeia a mulher minúscula, ele a chama Pequena Flor.

A notícia da descoberta desse ser mínimo vivendo nos confins da floresta chega às casas de família da cidade. Em cada casa, em cada família, em cada mulher 
que se confronta com a existência dessa mulher minúscula, a ordem cotidiana bascula. Em uma casa, a visão da fotografia de Pequena Flor no jornal é insuportável; em outra, não teria sido prudente deixá-la sozinha com a dona da casa e com a bondade perversa que ela experimenta pela minúscula criatura. Ainda em outro lar, cada um a quis para si mesmo "aquela coisa miúda e indomável”, e Clarice Lispector acrescenta: “E, mesmo, quem já não desejou possuir um ser humano só para si?” (idem, p. 73). O amor possessivo e a bondade perversa vão até o extremo de uma mulher que se lembra do seu tempo no orfanato — não tendo bonecas com as quais brincar, as meninas tinham escondido a morte de uma de suas colegas e a tinham guardado em um armário para brincar com ela como se brinca com uma boneca.

Do que se trata na aparição dessa estranha mulher minúscula? Trata-se do surgimento de uma alteridade radical. Mas temos também, através da descoberta da pequena mulher pelas mulheres da cidade, a revelação de uma dimensão do amor marcada pela possessão que chega ao extremo da crueldade. Curiosamente, a crueldade aqui não está do lado do primitivo, da floresta ou do animal, onde o amor consiste em não ter sido devorado, a gozar da vida, mas do lado da civilização. Da frase de Clarice: “E, mesmo, quem já não desejou possuir um ser humano só para si?” (idem), ecoa o desejo de ter filhos. A crueldade situa-se então do lado de um amor próximo do cuidado e do zelo, tão definidores do amor materno. Seja no desejo de possuir um ser humano só para si, seja na brincadeira de boneca com a menina morta, trata-se do que está em jogo na maternidade - um objeto real para si. Do lado da civilização, portanto, o amor materno exibe-se em sua vertente possessiva, que poderíamos definir como gozo fálico. Entretanto, na medida que vai até o horror da morte, o amor materno excede esse gozo fálico, não se deixando recobrir inteiramente por ele.

Há algo aí que aponta para um gozo excessivo e sem limite. Que não nos deixemos enganar por uma dicotomia fácil: as mulheres da cidade e o gozo fálico de um lado e, de outro, a menor mulher do mundo e o gozo outro. A mulher é não-toda, não só o amor materno das mulheres da cidade excede o gozo fálico, como a gravidez de Pequena Flor se divide entre os dois gozos. No coração da menor mulher do mundo, vivendo em uma tribo cuja linguagem é constituída por muito poucas palavras, a comunicação se fazendo por gestos e gritos animais, mesmo nessa "coisa rara”, o amor preserva seu lado possessivo, marcado pelo gozo fálico. Pequena Flor traz, ela também, a dimensão do amor possessivo. Ela ama o explorador por seu anel, por suas botas, por sua diferença, ela quer possuir.

Curiosamente, Pequena Flor está grávida e sua gravidez aproxima-se do grotesco, do animalesco, daquilo que não fala e que goza da vida, de um gozo outro que o gozo fálico. Seu pequeno ventre avolumado pela gravidez, seu riso 
de coisa que não fala causam horror ao explorador. O amor de Pequena Flor por ele também o desconcerta, o coloca no embaraço, o faz perder seus pontos de referência. As certezas e o saber do explorador são abalados pela radical alteridade de Pequena Flor, não apenas porque ela é outro, mas porque ela surpreende e rompe com a expectativa do que o outro deve ser. Ela não se situa inteiramente nem do lado primitivo, não se reduzindo a essa ordem, mesmo se ela é também gozo da vida, aminalesco e excessivo, nem do lado da civilização, mesmo se marcada pelo gozo possessivo. Na gravidez de Pequena Flor, no horror provocado pelo seu ventre disforme, exibe-se mais uma vez a irredutibilidade do amor materno ao falo porque a maternidade também está aí colocada do lado do gozo da vida, animal e excessiva, vida não recoberta pelo significante.

\footnotetext{
"Metodicamente o explorador examinou com o olhar a barriguinha do menor ser humano maduro. Foi nesse instante que o explorador, pela primeria vez desde que a conhecera, em vez de sentir curiosidade ou exaltação ou vitória ou espírito científico, o explorador sentiu mal-estar.

É que a menor mulher do mundo estava rindo.

Estava rindo, quente, quente. Pequena Flor estava gozando a vida. A própria coisa rara estava tendo a inefável sensação de ainda não ter sido comida." (LISPECTOR, 1999, p. 73)
}

Pequena Flor ria e era um riso próprio àquele que não fala. O que desconcerta o explorador é este gozo outro, animalesco, excessivo, que não passa pelo significante. Pequena Flor revela que no interior das casas o amor traz em si um resto não assimilável, situado do lado do excesso, da crueldade, uma outra face do amor materno é assim revelada. Ora isso nos faz pensar a maternidade diferentemente: os animais indicam um tempo fora do tempo, pois fora da linguagem, o inumano, o selvagem, o gozo infinito e desregrado. Segundo Clarice, os animais não substituem jamais uma coisa por outra (LISPECTOR, 1999a). Assim, a maternidade não se reduz à cadeia de substituição de uma equivalência simbólica, ao contrário, a maternidade traz nela um resto que não é assimilável, situado do lado do excesso, que não faz série com os outros objetos. Outra face da maternidade é, deste modo, desvelada, ligada menos à série simbólica do que ao que não se encadeia e que, ao contrário, irrompe como evento único, impronunciável. Por isso: "Mãe é doida. É tão doida que dela nasceram filhos. Eu me alimento com ricas comidas e tu mamas em mim leite grosso e fosforescente. Eu sou o teu talismã" (idem, p. 110).

Sendo o primitivo, a vida de matéria elementar, a vida em seu gozo animal, o it dos animais, a floresta, Pequena Flor é o insignificante transformado em coisa rara. Seu gozo é animal, infinito, como só o gozo daquele que não fala pode 
ser. Ela goza da vida, ela goza do fato de não ter sido devorada. Ela é o pequeno detalhe insignificante que revela, de um lado, o gozo animal e excessivo da vida na floresta e, de outro, a dimensão cruel do nosso amor civilizado cujo caráter perverso é ilustrado pela lembrança da órfã morta. No nosso mundo civilizado, o amor também devora. O efeito produzido por esse ser minúsculo é a revelação do gozo excessivo no interior mesmo do amor civilizado.

Temos primeiro o mundo da floresta com seus seres desprovidos de linguagem, onde quase sempre as crianças não gozam longo tempo da liberdade porque serão devoradas, mas onde reina uma espécie de felicidade de um gozo que supomos e que atribuimos aos animais. Em seguida, a crueldade surge não do lado do mundo selvagem, mas do lado da civilização, no interior das casas e no coração do sentimento mais nobre que pode existir, no coração do amor. O desvelamento dessa outra dimensão do amor é desencadeado pela existência dessa mulher outra, negra e minúscula, Pequena Flor. Mas, nova inversão, no interior da floresta, no coração de Pequena Flor, vemos nascer o lado possessivo do amor. Que não nos enganemos, esta dimensão do amor não o desvaloriza, nem contribui a uma assimilação entre Pequena Flor e as mulheres da cidade, o mal-estar permanece no embaraço do explorador que perde suas referências, pois a menor mulher do mundo instaura a diferença e o desconhecido.

Em Perto do coração selvagem (LISPECTOR, 1995), primeiro livro de Clarice, já vemos tomar forma esta concepção curiosa da maternidade. Em um capítulo intitulado "A mulher da voz e Joana”, a protagonista fascina-se pela voz de uma mulher que parece chamar em um apelo intransitivo, sem objeto. Por intermédio da voz desta mulher, Joana descobre o segredo de simplesmente viver. A mulher da voz, com sua cintura engrossada pela maternidade, com sua voz vinda do fundo da garganta, como se se tratasse de uma voz de antes do significante, de antes da palavra, parece encarnar nela mesma o "selvagem coração da vida". Ela é aquela que segue seu destino biológico de mulher, mas o curioso é que ele não se recobre inteiramente pela reprodução — não se trata de ser mãe, mas simplesmente de ser. "O principal — incluindo o passado, o presente e o futuro - é que estava viva. Esse é o pano de fundo da narrativa”, escreve Clarice sobre a mulher da voz (idem, p.87) A mulher simplesmente fêmea não é aquela que espera um filho, é aquela que não espera nada, que é a vida que corre em seu corpo. Podemos dizer que o "selvagem coração da vida" situa-se, em Clarice, do lado da mãe. Concebe-se, assim, o feminino como origem, mas segundo uma posição subjetiva que engaja uma relação outra à maternidade, apontando para uma lógica além do falo.

Clarice contrapõe à imagem da mãe como a mulher puramente mulher, perfeitamente mulher, uma outra imagem na qual a mulher corresponde à vida no que ela tem de horror e de inumana - a vida crua. Seja na mulher da voz, seja 
em Pequena Flor, seja na barata de G.H, a vida e a maternidade estão situadas do lado do que é bruto, orgânico, imundo, como nos mostra o seguinte trecho de A paixão segundo G.H., no qual a barata é a vida olhando G.H., vida horrível, imunda e crua, plasma e lama:

\footnotetext{
"Ali estava eu boquiaberta e ofendida e recuada — diante do ser empoeirado que me olhava. Toma o que eu vi: pois o que eu via com um constrangimento tão penoso e tão espantado e tão inocente, o que eu via era a vida me olhando.

Como chamar de outro modo aquilo horrível e cru, matéria-prima e plasma seco, que ali estava, enquanto eu recuava para dentro de mim em náusea seca, eu caindo séculos e séculos dentro de uma lama — era lama, e nem sequer lama já seca mas lama ainda úmida e ainda viva, era uma lama onde se remexiam com lentidão insuportável as raízes de minha identidade.” (LISPECTOR, 1996, p. 38)
}

III

Podemos pensar que se, para Freud, a verdade do desejo feminino seria significada pelo desejo de ser mãe por meio da equivalência falo-criança e seu conseqüente tamponamento da falta; para Lacan, essa verdade seria a ser investigada na divisão da mulher entre os dois gozos, que aponta não para a possibilidade de completude, mas para um gozo além do fálico ligado ao real da estrutura (Cf. LACAN, 1972-1973/1975).

É verdade que Lacan sempre se referiu à existência de um gozo suplementar ao qual as mulheres teriam acesso com bastante prudência, sempre como algo a ser verificado, hipótese a ser investigada. As figuras da maternidade em Clarice Lispector nos fazem pensar que a mulher não está toda na maternidade ou na histeria ou na mascarada, e que é aberta a ela a possibilidade de acesso a um gozo diferente do fálico. Parece-nos que há, na maternidade, algo que revela a existência desse gozo outro, que não se reduz ao falo, que aponta para a impossilidade de reconciliação entre o simbólico e o real.

Resta ainda uma pergunta. A feminilidade seria um modo do abordar a falta e a castração. Há que se interrogar se não seria possível fazê-lo por outra via diferente da do falo ou da criança, como seu substituto. É ainda preciso dizer que o valor de algumas proposições freudianas acerca da maternidade devem ser repensadas hoje: A criança é ainda investida no mundo contemporâneo de um tal valor fálico? Muito freqüentemente a maternidade é descrita hoje como uma série de privações e a criança como aquele que tudo rouba da mãe, seu tempo, sua carreira profissional, sua beleza, etc. Além disso, há algumas décadas as mulheres passaram a ter acesso ao gozo fálico de maneira nunca antes vista.

Quais seriam as conseqüências dessa transformação? Que as mulheres tenham acesso a uma infinidade de possibilidades no campo do gozo fálico não significa 
que A mulher exista. Ao contrário, um excesso de gozo fálico seria obstáculo ao gozo Outro. Contudo, há que se precisar que não é pela rejeição do falo que a mulher teria acesso ao gozo feminino para além do falo, mas é recuperando "sua castração tomada como empréstimo do outro” (MOREL, 1996, p.130). O nãotodo não é a anulação do significante falo, o que poderia nos levar a responder a nossa pergunta pela via da criança. A criança poderia vir a ser a presença fálica contingente que confrontaria a mulher à sua castração e não à completude. Não que toda a maternidade deva ser assim tomada, mas que algo dela, da criança e da experiência de gestação, traga como possibilidade o acesso ao gozo feminino, na medida que podem funcionar, por algum tempo, como um encontro, não com a própria mãe, mas com o S (de A barrado), com o além do simbólico.

Quanto ao modo de suplência da inexistência da relação sexual do lado da mulher, permanece a questão de se saber se todas as transformações da nossa sociedade não levaram a modificações quanto à economia das pulsões e os modos de gozo das mulheres. Desde 1932, data da última conferência de Freud sobre a sexualidade feminina, na qual ele faz equivaler o ser mulher e o ser mãe, as sociedades ocidentais passaram por consideráveis transformações, o tempo em que a única via aberta às mulheres era a maternidade é, hoje, passado.

As modificações dos desejos das mulheres são evidentes e muitos são os dados para pensar que a possibilidade de acesso ao gozo fálico, para as mulheres, multiplicou-se. As novas configurações familiares — educar uma criança sozinha ou com outra mulher, as famílias monoparentais cada vez mais numerosas, as mulheres encarragadas da família, etc. — as novas imagens e os novos símbolos da mulher, o discurso em relação ao gozo sexual, definindo-o não apenas como legítmo, mas sobretudo com um bem ao qual todos tem direito, independente do amor ou da reprodução, todos os campos abertos às mulheres no mundo do trabalho e da vida profissional são evidências da abertura de novas possibilidades e destinos.

A mãe, genitora, não é um semblante, contrariamente ao pai que, enquanto Nome, é um semblante e não um genitor. Vemos aí que a disjunção entre a função de reprodução, real, na qual se situa a mãe como genitora, e a função de semblante, simbólica, encontra-se invertida em um e outro (SOLER, 2003, p.105). Ora, para além da reprodução, a função de maternagem é, e assim foi desde sempre, substituível como testemunham as amas de leite e as adoções. O clássico livro de Badinter, O amor incerto (1980), nos oferece uma excelente compreensão de como o amor materno é resultado, não de um instinto materno, mas de uma construção histórica, social e cultural e de como os cuidados com a criança podem ser desempenhados por substitutos.

Entretanto, o que vemos na atualidade como correlato ao declínio do pai é a idealização da mãe. Nas novas configurações familiares, a mãe, ou seu substitu- 
to, torna-se freqüentemente o único parceiro estável da criança (idem, p.106). Interessa-nos as conseqüências subjetivas destas configurações concretas nas marcas deixadas no sujeito pelo Outro primordial.

Soler chama nossa atenção para o fato de que Lacan se interessou primeiramente pelo desejo da mãe, contrapondo a mulher à mãe do amor. A mãe foi então a mulher do pai, tal como ela aparece na metáfora paterna, em sua leitura do Édipo freudiano. Entretanto, o além do Édipo nos fala de uma mulher não toda ocupada pelo homem ou pela criança. Podemos dizer que o que está indicado na noção do não-todo é que há algo da mãe que não se recobre pela lógica fálica e que é pela via do gozo que podemos pensar a mãe para além do Édipo.

O acesso das mulheres ao gozo fálico poderia nos levar a crer que A mulher se inscreve no simbólico. Mas Clarice nos revela que a mulher é não toda na lógica fálica e que mesmo a maternidade, modo freqüentemente privilegiado de relação com o falo, pode ser tomada como uma via de acesso ao gozo feminino, na medida que algo do real resiste aí a uma apreensão pelo simbólico. Uma interrogação sobre o feminino leva sempre a um além do significante e da castração, ao impossível de simbolizar ou de subjetivar que podem estar presentes na experiência da gestação e do parto.

Recebido em 20/2/2006. Aprovado em 15/8/2006.

\section{REFERÊNCIAS}

BADINTER, E. (1980) O amor incerto: História do amor maternal do séc. XVII ao séc. XX. Lisboa: Relógio D’Água.

DURAS, M. (1993) Moderato Cantabile. Paris: Minuit. (1998) India Song. Paris: Gallimard.

FREUD, S. (1969) Coleção Standard Brasileira. Rio de Janeiro: Imago.

(1931) "Sexualidade Feminilidade”, v. XXI, p. 255-279.

(1932) "Feminilidade”, v. XXII, p. 139-165.

KRISTEVA, J. (1999) “Stabat Mater”, in: Histoires d'amour. Paris: Folio essais Denoël.

LACAN, J. (1960/1966) "Propos directives pour un congrès sur la sexualité féminine”, in Écrits. Paris: Seuil.

(1970-1971) Le séminaire livre XVIII, D’un discours qui ne serait pas du semblant. Inédito. Texto não publicado oficialmente (exemplares mimeografados). 
(1971-1972) Le savoir du psychanalyste. Conférènce à Saînte-Anne. Inédito. Texto não publicado oficialmente (exemplares mimeografados).

(1972/1973) L'étourdit. Scilicet — Revue du Champ Freudien, n.4. Paris: Seuil, p. 5-52.

(1972-1973/1975) Le séminaire livre XX, Encore. Paris: Seuil.

( 1969/1986) Deux notes sur l'enfant. Ornicar?, n. 37. Paris:

Navarin, p.13-14.

LEMOINE-LUCCIONI, E. (1982) “Grossesse et féminité, in: Partage des femmes. Paris: Points Seuil.

LISPECTOR, C. (1984) A hora da estrela. Rio de Janeiro: Nova Fronteira. .(1995) Perto do coração selvagem. Rio de Janeiro: Francisco Alves. (1996) A paixão segundo G.H. Edição crítica. (Org. Bendito Nunes). Espanha: Edições Unesco.

. (1999) “A menor mulher do mundo”, in: Laços de família. Rio de Janeiro: Rocco.

(1999a) Um sopro de vida. Rio de Janeiro: Rocco.

MOREL, G. 1996. "Anatomia analítica”, in FORBES, J. (org.). Psicanálise: Problemas ao feminino. São Paulo: Papirus.

SOLER, C. (2003) Ce que Lacan disait des femmes. Paris: Editions du Champ Lacanien.

SILVESTRE, D. (1996) “Le semblant phallique de la maternité”, in: Quarto — Revue de psychanalyse École de la Cause Freudienne - ACF en Belgique, n. 52. Bruxelas: Agalma-Seuil, p.16-22.

Cristina Marcos

cristinamarcos@terra.com.br 